\title{
Geomagnetic Shielding Property and Mechanism of Fe-Ni Laminated Composite
}

\author{
Xiangyu Ma $\cdot$ Qiang Zhang $\cdot$ Xiang Chen $\cdot$ Gaohui Wu
}

Received: 30 May 2014/Revised: 31 August 2014/Published online: 30 September 2014

(C) The Chinese Society for Metals and Springer-Verlag Berlin Heidelberg 2014

\begin{abstract}
Ni layers were deposited on the two sides of pure Fe substrate by using electroplating to form $\mathrm{Ni} / \mathrm{Fe} / \mathrm{Ni}$ diffusion couple. After diffusion heat treatment, $\mathrm{Fe}-\mathrm{Ni}$ laminated composite was obtained with $\mathrm{Fe}-\mathrm{Ni}$ alloy/ $/ \mathrm{Fe} / \mathrm{Fe}-\mathrm{Ni}$ alloy structure. The results indicate that the $\mathrm{Fe}-\mathrm{Ni}$ layers combine well with the substrate and the $\mathrm{Fe}-\mathrm{Ni} / \mathrm{Fe}$ interface presents an interlocking microstructure with small-size grains. The concentration of element $\mathrm{Ni}$ in the $\mathrm{Fe}-\mathrm{Ni}$ layer decreases from surface to interior exhibiting a gradient distribution. Geomagnetic shielding factor (SF) of Fe-Ni laminated composite can reach as high as 22.6, which is about seven times of that of pure Fe substrate. Mathematical equation of SF for laminated structure was derived according to magnetic circuit and resistance theory. The theoretical expression reveals that parameters such as the thickness and magnetic permeability of the shield material play an important role in the magnetic shielding behavior and the theoretical calculation results of SF coincide well with our experimental values.
\end{abstract}

KEY WORDS: Fe-Ni laminated composite; Initial permeability; Magnetic shield; Shielding factor

\section{Introduction}

Geomagnetic field exists in any place of the earth and its magnetic field intensity is very low with a magnitude ranging from $2.5 \times 10^{-5}$ to $6.5 \times 10^{-5} \mathrm{~T}$ at the Earth's surface [1]. In some cases of sensitive electrical and highaccuracy electronic sensors, their tolerances to environmental magnetic field are very low, and even the field like geomagnetic field may cause disturbing and even the

Available online at http://link.springer.com/journal/40195

X. Ma $\cdot$ Q. Zhang $(\bowtie) \cdot$ X. Chen $\cdot$ G. Wu $(\bowtie)$

School of Material Science and Engineering, Harbin Institute of

Technology, Harbin 150001, China

e-mail: zhang_tsiang@hit.edu.cn

$\mathrm{G} . \mathrm{Wu}$

e-mail:wugh@hit.edu.cn

X. Chen

Department of Applied Science and Technology, Politecnico di Torino, 10129 Turin, Italy sensor becomes disabler [2]. Therefore, it is necessary to provide magnetic protection against the geomagnetic field so as to ensure their normal functions in an Earth environment. The intensity of geomagnetic field fluctuates with no regularity as time goes by, which can be divided into the mean field intensity and fluctuating value. Therefore, the geomagnetic field shield includes static magnetic shielding and low frequency magnetic shielding [3].

Magnetic shielding can be achieved through shunting effect of magnetic materials with high magnetic permeability. As a traditional magnetic shielding material, permalloy has high magnetic permeability and excellent shielding property. However, it is also highly sensitive to stress and microstructure, and even a knock during assembling process could worsen its magnetic properties and shielding effectiveness. The magnetic property of amorphous soft magnetic alloy is not affected by machining. Through structural design, this alloy was reported to produce highly effective magnetic shield [4-6]. Structural design [7, 8] and effectiveness calculation of magnetic shield $[9,10]$ are the two main issues in the magnetic 
shielding field. One interesting structural design is to use laminated composite as magnetic shielding material, which can be prepared by several different approaches, such as combining sheets of polymer and soft magnetic metal under pressure or alternatively depositing films of oxide and soft magnetic metal. By adjusting the thickness of each layer, the shielding effectiveness of laminated composite can be tailored $[11,12]$.

In this study, we manufactured a special laminated composite, composed of two layers of high-magnetic-permeability $\mathrm{Fe}-\mathrm{Ni}$ alloy (permalloy) on the surface and one layer of pure $\mathrm{Fe}$ in the interior. The shielding factor of this laminated composite was determined experimentally and theoretically. Meanwhile, the influencing factors of SF were discussed and the connotative magnetic shielding mechanism was revealed.

\section{Experimental}

Commercial electromagnetic pure iron (DT4E) in the form of cold-rolled plate was chosen as the substrate material with a thickness of $0.5 \mathrm{~mm}$. The pretreatment processes including alkaline degreasing, sulfuric acid excitation, and water washing before electroplate were conducted. The plating solution was composed of nickel sulfate (250-350 g/L), nickel chloride (30-60 g/L), and boric acid (30-40 g/L). And the process conditions included temperature $\left(45-60{ }^{\circ} \mathrm{C}\right.$ ) and cathodic current density (1-2.5 A/dm $\left.{ }^{2}\right) . \mathrm{Ni}$ layers were deposited on the two sides of pure Fe substrate to form $\mathrm{Ni} / \mathrm{Fe} / \mathrm{Ni}$ diffusion couple. According to heat treatment regime of perm alloy and DT4E, the diffusion heat treatment was established to obtain preferable magnetic property. The $\mathrm{Ni} / \mathrm{Fe} / \mathrm{Ni}$ couple was heated up to $1,200{ }^{\circ} \mathrm{C}$ for $1 \mathrm{~h}$, cooled to $880{ }^{\circ} \mathrm{C}$, and then kept at $880{ }^{\circ} \mathrm{C}$ for $4 \mathrm{~h}$ in vacuum. The heating rate was $10^{\circ} \mathrm{C} / \mathrm{min}$, while the rate of heating and cooling around $880^{\circ} \mathrm{C}$ should be very slow, and then specimens were cooled in furnace. The Fe-Ni laminated composite obtained was marked by $\mathrm{Fe}-\mathrm{Ni} / \mathrm{Fe} / \mathrm{Fe}-\mathrm{Ni}$ furnace cooling. In addition, the $\mathrm{Fe}-\mathrm{Ni}$ laminated composite was further heat-treated by air quenching from $600{ }^{\circ} \mathrm{C}$ and which was marked by $\mathrm{Fe}-\mathrm{Ni} / \mathrm{Fe} / \mathrm{Fe}-\mathrm{Ni}$ air cooling.

The metallographic specimens were prepared with polishing and chemical etching by $3 \%$ nital after cutting from the $\mathrm{Fe}-\mathrm{Ni}$ laminated composite. The $\mathrm{Fe}-\mathrm{Ni}$ layer/Fe interface in cross section was observed using optical microcopy (OM, ZEISS-40MAT). Energy dispersive spectroscopy (EDS, S-4700) was used to measure the $\mathrm{Ni}$ element content distribution. Six specimens were bonded side by side using organic glue. After grinding cross section, the phases were identified by X-ray diffraction (XRD, D/MAX200, $\mathrm{Cu} K_{\alpha}, 40 \mathrm{kV}, 100 \mathrm{~mA}$ ). The pure iron square tube $(20 \mathrm{~mm} \times 20 \mathrm{~mm} \times 80 \mathrm{~mm})$ was prepared by mechanical bending and arc welding. With nickel electroplating and diffusion heat treatment, the square tube of $\mathrm{Fe}-\mathrm{Ni}$ laminated composite was obtained for magnetic shielding measurement. The intensity of magnetic field was measured using the hall probe of gauss meter (Lake Shore 421). The geomagnetic shielding factor (SF) is expressed as $H_{0} / H_{\mathrm{S}}$, where $H_{\mathrm{S}}$ is the magnetic field with shield present and $H_{0}$ is the magnetic field in the same point without shield. The measured direction was parallel to the cross section of square tube.

\section{Results and Discussion}

\subsection{Microstructure}

Figure 1 shows the overall cross-sectional and local oblique-sectional morphology of $\mathrm{Fe}-\mathrm{Ni}$ laminated composite separately. In the initial $\mathrm{Ni}$-coated Fe specimen, Fe grains exhibit elongated structure and fine combination exists between Ni coating and the Fe substrate with a clean and flat interface. Then the cold rolled structure in Fe substrate turned into annealed structure with equiaxial grains after heat treatment, meanwhile $\mathrm{Fe}-\mathrm{Ni}$ alloy layer was formed on the surface and interlocking interface was developed in between.

Generally speaking, inter-diffusion between $\mathrm{Fe}$ and $\mathrm{Ni}$ generates the gradient elemental distribution in the $\mathrm{Fe}-\mathrm{Ni}$ layer, which was examined through EDS linear scanning, and the result is presented in Fig. 2. The Ni content in the $\mathrm{Fe}-\mathrm{Ni}$ layer gradually decreased from the surface to the interior, accordingly the $\mathrm{Fe}-\mathrm{Ni}$ alloy layer could be divided into surface layer ( $8 \mu \mathrm{m}, \mathrm{Ni} 70-80$ at.\%) and transition layer $(17 \mu \mathrm{m}, \mathrm{Ni}<70$ at.\%). However, in reality, $\mathrm{Fe}-\mathrm{Ni}$ inter-diffusion did not occur uniformly. The boundary diffusion took place faster than the volume diffusion, which resulted in the interlocking interface structure. To further observe interface structure, we increased the observing area by polishing the $\mathrm{Fe}-\mathrm{Ni} / \mathrm{Fe} / \mathrm{Fe}-\mathrm{Ni}$-laminated composite obliquely (Fig. 1b) rather than perpendicularly, and the result is shown in Fig. 1d. More details were revealed from the morphological observation in the enlarged interfacial zone, and a lot of grains were surrounded by the fast boundary diffusion paths which restricted them from growing up.

XRD analysis was carried out to identify the phase composition in $\mathrm{Fe}-\mathrm{Ni}$ laminated composite, as shown in Fig. 3. From the XRD pattern, only ferrite and Fe-Ni solid solution phases were detected and apparently the ferrite phase has much higher content than the Fe-Ni solid solution phase by comparing their intensity. 

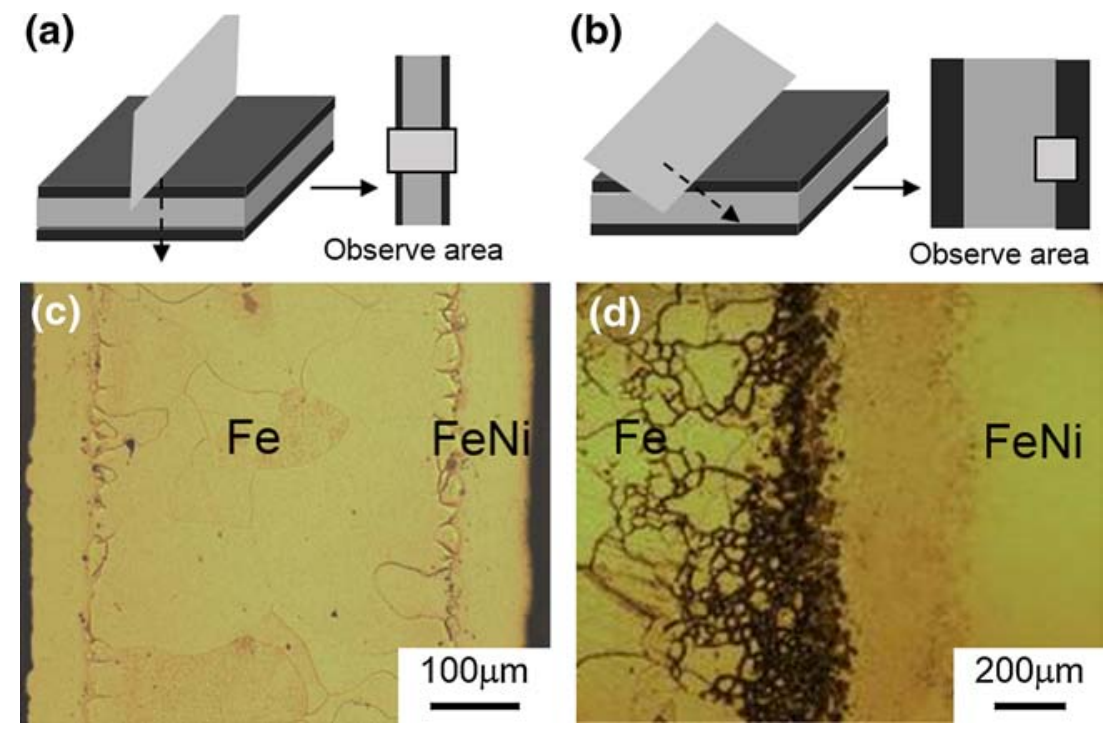

Fig. 1 Schematic showing OM specimens preparation and metallographic morphology of Fe-Ni laminated composite: a, c Cross section; b, d oblique section

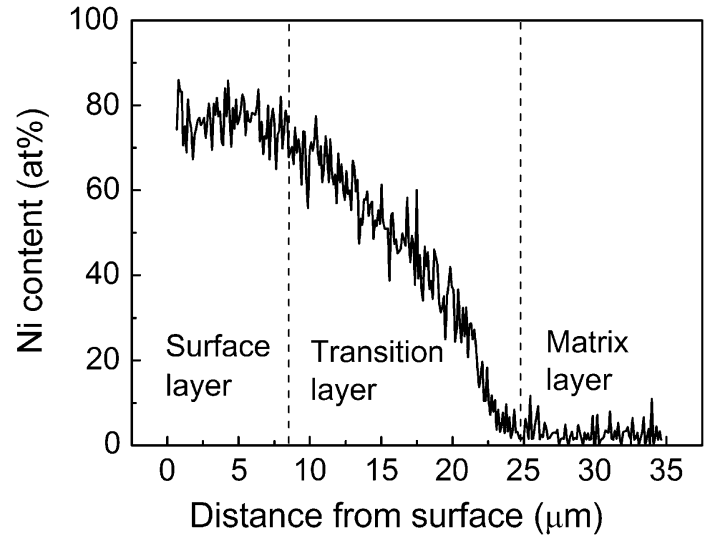

Fig. $2 \mathrm{Ni}$ element distribution in the surface layer of $\mathrm{Fe}-\mathrm{Ni} / \mathrm{Fe} / \mathrm{Fe}-\mathrm{Ni}$ laminated composite

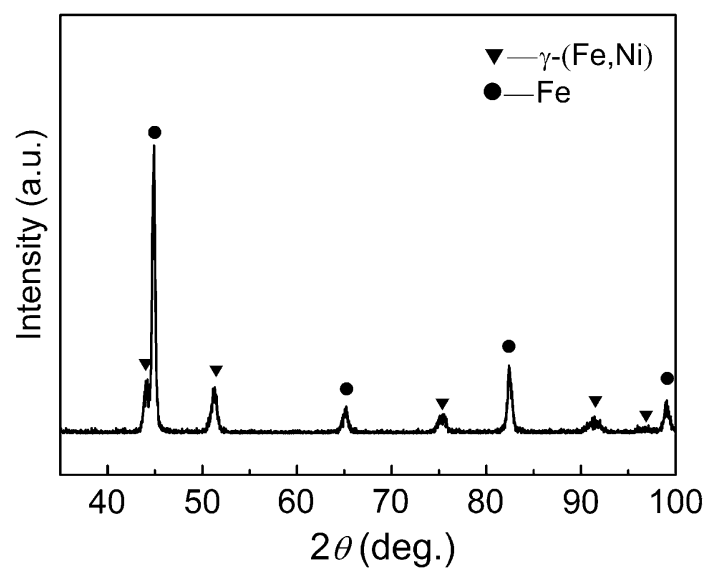

Fig. 3 XRD pattern of Fe-Ni laminated composite on cross section

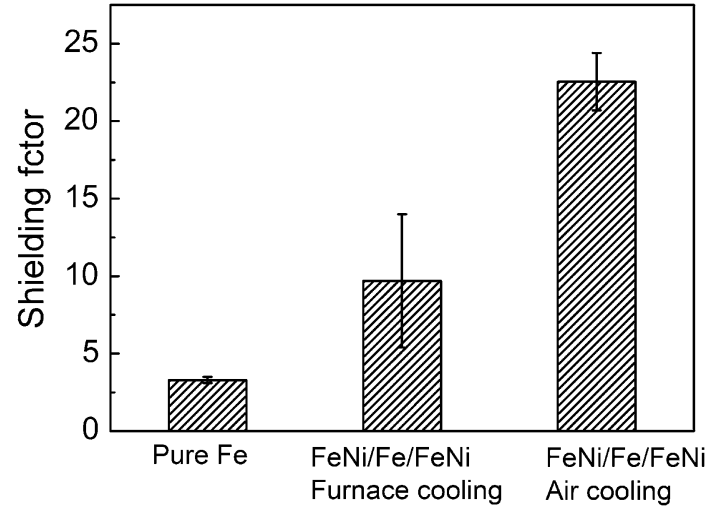

Fig. 4 Geomagnetic shielding factor of different structures and cooling conditions

\subsection{Geomagnetic Shielding Property}

Geomagnetic shielding factor (SF) of substrate and $\mathrm{Fe}-\mathrm{Ni}$ laminated composite are plotted separately in Fig. 4. The $\mathrm{SF}$ of $\mathrm{Fe}-\mathrm{Ni}$ laminated composite reaches 22.6, about seven times of the value of pure Fe substrate. In the case of furnace cooling, the SF of $\mathrm{Fe}-\mathrm{Ni}$ laminated composite ( $\mathrm{Fe}-$ $\mathrm{Ni} / \mathrm{Fe} / \mathrm{Fe}-\mathrm{Ni}$ furnace cooling) is only 9.7 , whereas in the case of air cooling (through further air quenching at $\left.600{ }^{\circ} \mathrm{C}\right)$, the $\mathrm{SF}$ of composite ( $\mathrm{Fe}-\mathrm{Ni} / \mathrm{Fe} / \mathrm{Fe}-\mathrm{Ni}$ air cooling) arrives at 22.6.

Figure 5 shows the relative initial permeability of $\mathrm{Fe}-\mathrm{Ni}$ alloy with different $\mathrm{Ni}$ content under different cooling conditions. Compared with pure $\mathrm{Fe}, \mathrm{Ni}$ alloying treatment would improve the initial permeability effectively with 


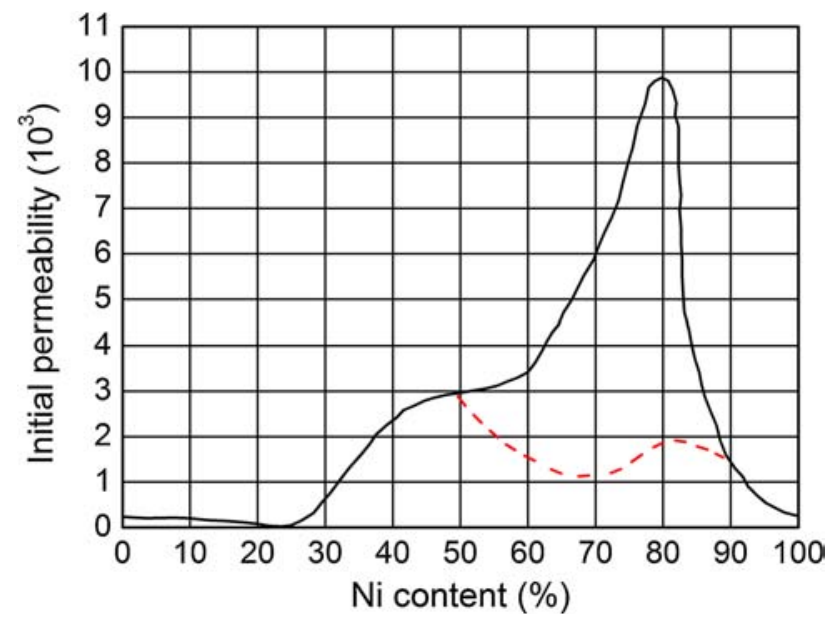

Fig. 5 Initial permeability of $\mathrm{Fe}-\mathrm{Ni}$ alloy under different cooling conditions [3]
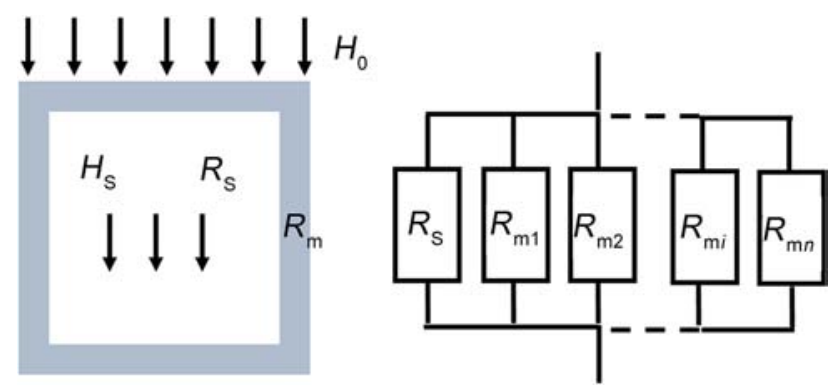

Fig. 6 Schematic diagram of magnetic shielding and equivalent magnetic circuit

both cooling conditions. Especially in the range with (50-90) at.\% of $\mathrm{Ni}$, the formation of ordered phase $\mathrm{Fe}-\mathrm{Ni}_{3}$ is believed to play an important role in the magnetic property. When cooling from high temperature, disordered $\mathrm{Fe}-\mathrm{Ni}_{3}$ would turn into ordered $\mathrm{Fe}-\mathrm{Ni}_{3}$, which would worsen the magnetic property of $\mathrm{Fe}-\mathrm{Ni}$ alloy. Suitable fast cooling treatment can effectively control the degree of $\mathrm{Fe}-$ $\mathrm{Ni}_{3}$ ordering and therefore improve the initial permeability property. Taking these into account, if we consider $\mathrm{Fe}-\mathrm{Ni}$ laminated composite as several layers of $\mathrm{Fe}-\mathrm{Ni}$ alloys, the improvement of geomagnetic shielding factor through $\mathrm{Ni}$ alloying and air quenching can be well understood.

\subsection{Shielding Factor Calculation}

Square shield is put in static magnetic field with the magnetic field direction being parallel to the cross section of shield, as shown in Fig. 6. The intensity of outside magnetic field is $H_{0}$, and the intensity of magnetic field in the shied is $H_{\mathrm{S}}$. So, shielding factor (SF) can be expressed as $H_{0} / H_{\mathrm{S}}$. The calculation of SF is similar to the equivalent circuit method by considering relevant components into magnetic resistance elements.

The magnetic resistance of the shielding area is $R_{\mathrm{S}}$. The shield is considered to be composed of several magnetic conductive layers. Each magnetic conductive layer has its individual resistance denoted as $R_{\mathrm{m} i}$, which sums to $R_{\mathrm{m}}$. According to the equivalent magnetic circuit theory [13], when the thickness of the shield is much less than the size of the shielding area, the SF can be expressed as:

$\mathrm{SF}=1+\frac{R_{\mathrm{S}}}{R_{\mathrm{m}}}$

Meanwhile, in a parallel circuit, total resistance $R_{\mathrm{m}}$ can be written as

$R_{\mathrm{m}}=\frac{1}{\frac{1}{R_{\mathrm{m} 1}}+\frac{1}{R_{\mathrm{m} 2}}+\cdots+\frac{1}{R_{\mathrm{m} n}}}=\frac{1}{\sum_{i=1}^{n} \frac{1}{R_{\mathrm{m} i}}}$.

Thus, the SF becomes

$\mathrm{SF}=1+\sum_{i=1}^{n} \frac{R_{\mathrm{S}}}{R_{\mathrm{m} i}}$

The magnetic resistance $R$ can be expressed as [14]

$R=\frac{H l}{B S}=\frac{l}{\mu S}$,

where $\mu$ is the magnetic permeability in $\mathrm{H} / \mathrm{m}, S$ is the crosssectional area of magnetic circuit in $\mathrm{m}^{2}$, and $l$ is the length of magnetic circuit in $\mathrm{m}$.

From Eq. (4), it can obtained that

$\frac{R_{\mathrm{S}}}{R_{\mathrm{m} i}}=\frac{2}{a} \mu_{\mathrm{ri} i} d_{i}$,

where $a$ is the length of side of shield area in $\mathrm{m}, \mu_{\mathrm{ri}}$ is the relative initial permeability of the $i$ th layer, and $d_{i}$ is the thickness of the $i$ th layer.

Combining Eq. (3) and Eq. (5), the SF of the $n$-layer magnetic shield can be expressed as:

$\mathrm{SF}=1+\frac{2}{a} \sum_{i=1}^{n} \mu_{\mathrm{ri}} d_{i}$

In the case with a single layer of pure Fe substrate, the $\mathrm{SF}$ can be expressed as:

$\mathrm{SF}=1+\frac{2}{a} \mu_{\mathrm{r}} d$.

In the case with $\mathrm{Fe}-\mathrm{Ni}$ laminated composite, the shield can be divided into $\mathrm{Fe}-\mathrm{Ni} / \mathrm{Fe} / \mathrm{Fe}-\mathrm{Ni}$ three-layer structure at the macroscopic level and the $\mathrm{Fe}-\mathrm{Ni}$ layers can be further divided into infinite laminated structure. Accordingly, the SF can be written as: 

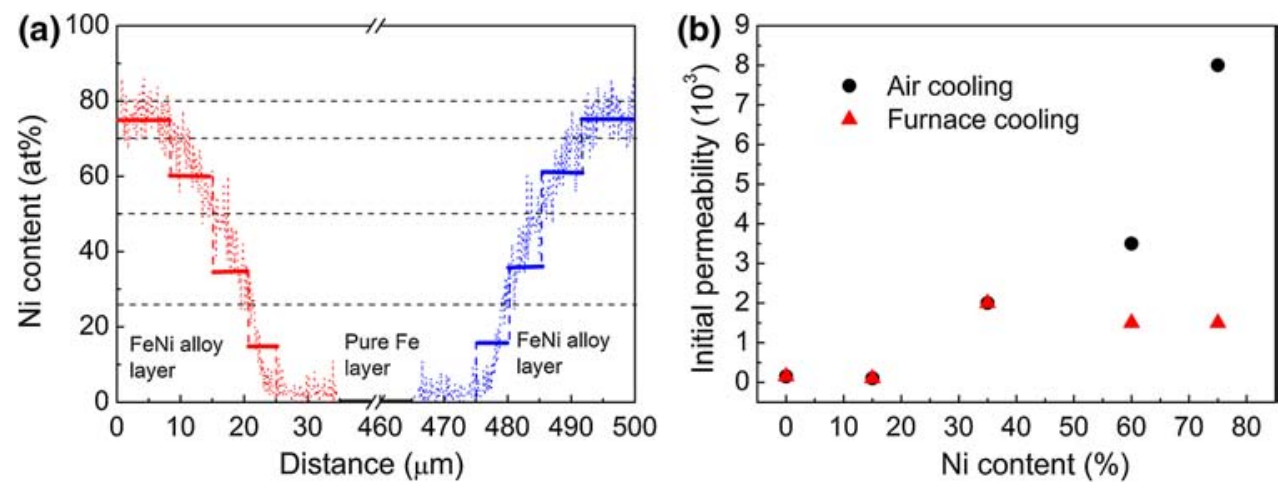

Fig. 7 Divided Fe-Ni alloy layers and initial permeability of each layer

Table 1 Thickness and initial permeability of each layer in $\mathrm{Fe}-\mathrm{Ni}$ laminated composite and $\mathrm{Fe}$ substrate

\begin{tabular}{lcll}
\hline Shield layer & Thickness $(\mu \mathrm{m})$ & \multicolumn{2}{l}{ Initial permeability $\mu_{i}$} \\
\cline { 3 - 4 } & & $\begin{array}{l}\text { Furnace } \\
\text { cooling }\end{array}$ & Air cooling \\
& 500 & 50 & 50 \\
\hline Fe substrate & & & \\
Fe-Ni/Fe/Fe-Ni & 8 & $1.5 \times 10^{3}$ & $8 \times 10^{3}$ \\
Ni$_{75}$ layer (70-80\%) & 8 & $1.5 \times 10^{3}$ & $3.5 \times 10^{3}$ \\
$\mathrm{Ni}_{60}$ layer (50-70\%) & 6 & $2.0 \times 10^{3}$ & $2.0 \times 10^{3}$ \\
$\mathrm{Ni}_{35}$ layer (25-50\%) & 6 & 100 & 100 \\
$\mathrm{Ni}_{15}$ layer (0-25\%) & 5 & 150 & 150 \\
$\mathrm{Pure} \mathrm{Fe}$ & 450 & & \\
\hline
\end{tabular}

$\mathrm{SF}=1$

$$
+\frac{2}{a}\left(\sum \mu_{\mathrm{r}-\mathrm{FeNi}} d_{\mathrm{FeNi}}+\mu_{\mathrm{r}-\mathrm{Fe}} d_{\mathrm{Fe}}+\sum \mu_{\mathrm{r}-\mathrm{FeNi}} d_{\mathrm{FeNi}}\right) .
$$

In this study, the thickness of the $\mathrm{Fe}-\mathrm{Ni}$ laminated composite is $500 \mu \mathrm{m}$ in total, which includes two layers of $\mathrm{Fe}-\mathrm{Ni}$ alloy $(25 \mu \mathrm{m})$ and the remaining $\mathrm{Fe}$ substrate $(450 \mu \mathrm{m})$, as shown in Fig. 7. Fe-Ni alloy layer can be divided into several layers with different $\mathrm{Ni}$ composition ranges. For example, from the surface to the center, the first (surface) layer includes the Ni content from 70 to 80 at.\%, which can be seen as a layer with 75 at. $\% \mathrm{Ni}$, named $\mathrm{Ni}_{75}$. The Ni content of second layer is from 50 to 70 at.\%, as the $\mathrm{Ni}_{60}$ layer. The third layer with (25-50) at.\% $\mathrm{Ni}$ is named $\mathrm{Ni}_{35}$. The $\mathrm{Ni}$ content range of last layer is (0-25) at.\%, named $\mathrm{Ni}_{15}$, which has low initial permeability.

The relative initial permeability of each layer in $\mathrm{Fe}-\mathrm{Ni}$ laminated composite is shown in Fig. 7b. According to the relationship between the initial permeability and Ni element content (Fig. 5), the initial permeability of pure Fe, $\mathrm{Ni}_{15}$, and $\mathrm{Ni}_{35}$ layers are not related to the cooling condition of heat treatment, which are 150,100 , and $2.0 \times 10^{3}$, respectively. However, the initial permeability of $\mathrm{Fe}-\mathrm{Ni}$ alloy with an $\mathrm{Ni}$ content from 50 to 90 at.\% is strongly
Table 2 Computed and measured values of SF

\begin{tabular}{llc}
\hline Shield layer & Computed SF & Measured SF \\
\hline Fe substrate & 3.5 & 3.3 \\
$\mathrm{Fe}-\mathrm{Ni} / \mathrm{Fe} / \mathrm{Fe}-\mathrm{Ni}$ & & \\
Furnace cooling & 14.5 & 9.7 \\
Air cooling & 27.3 & 22.6 \\
\hline
\end{tabular}

related to the cooling condition. The initial permeability of $\mathrm{Ni}_{75}$ layer increases from $1.5 \times 10^{3}$ under furnace cooling to $8.0 \times 10^{3}$ under air cooling. The initial permeability of $\mathrm{Ni}_{60}$ layer under furnace and air cooling are $1.5 \times 10^{3}$ and $3.5 \times 10^{3}$, separately. In addition, the initial permeability of cold-rolled $\mathrm{Fe}$ substrate is lower than that of pure $\mathrm{Fe}$ after annealing heat treatment, which was set at only 50 in the current calculation.

The thickness and the initial permeability of each layer in the $\mathrm{Fe}-\mathrm{Ni}$ laminated composite and pure Fe substrate in single layer shield are shown in Table 1 . The length of a side of shield area $(a)$ is $20 \mathrm{~mm}$.

According to the layer division method, Eq. (8) becomes

$$
\begin{aligned}
\mathrm{SF}=1 & +\frac{2}{a}\left[2 \times\left(\mu_{\mathrm{Ni} 75} d_{\mathrm{Ni} 75}+\mu_{\mathrm{Ni} 60} d_{\mathrm{Ni} 60}+\mu_{\mathrm{Ni} 35} d_{\mathrm{Ni} 35}\right.\right. \\
& \left.\left.+\mu_{\mathrm{Ni} 15} d_{\mathrm{Ni} 15}\right)+\mu_{\mathrm{r}-\mathrm{Fe}} d_{\mathrm{Fe}}\right] .
\end{aligned}
$$

Given the thickness $d$ and the relative initial permeability $\mu_{i}$, the computed values of SF of the substrate and $\mathrm{Fe}-\mathrm{Ni}$ laminated composite are obtained by Eq. (9), as shown in Table 2.

It is indicated that the computed value of $\mathrm{SF}$ of $\mathrm{Fe}-\mathrm{Ni} /$ $\mathrm{Fe} / \mathrm{Fe}-\mathrm{Ni}$ structure is higher than the measured value. The value of relative initial permeability for computing is obtained in literature, which is measured on the $\mathrm{Fe}-\mathrm{Ni}$ alloy with different $\mathrm{Ni}$ contents through the different optimal heat treatment. However, in this study, $\mathrm{Fe}-\mathrm{Ni}$ alloy layers are formed with gradient $\mathrm{Ni}$ element distribution after certain diffusion heat treatment, which is not the 
optical heat treatment process for each Fe-Ni layer. The actual magnetic properties (included initial permeability) of $\mathrm{Fe}-\mathrm{Ni}$ alloy layer will be lower than the value in literature. So, the measured value of SF is lower than the computed value. It is necessary to measure the actual initial permeability of each layer for computing the value of SF. The layer with certain Ni content is chosen to replace the $\mathrm{Fe}-\mathrm{Ni}$ layer to adjust the composition of the $\mathrm{Fe}-\mathrm{Ni}$ layer, as shown in Fig. 7a. The value of thickness and initial permeability of each $\mathrm{Fe}-\mathrm{Ni}$ alloy for computation can be taken as approximate value, which can bring the computing error of SF.

\subsection{Magnetic Shield Mechanism}

$\mathrm{Fe}-\mathrm{Ni}$ alloy layers are formed on the surface of pure Fe, which have very high magnetic permeability. The Fe-Ni laminated composite presents $\mathrm{Fe}-\mathrm{Ni} / \mathrm{Fe} / \mathrm{Fe}-\mathrm{Ni}$ three layered structure and infinite laminates in micro-level, which can shunt the magnetic field in parallel to achieve excellent shielding effectiveness. Compared with single layer (pure $\mathrm{Fe}$ substrate), $\mathrm{Fe}-\mathrm{Ni}$ laminated composite has higher shielding factor due to high permeability of $\mathrm{Fe}-\mathrm{Ni}$ alloy and parallel shunting of each layer.

As can be seen from the computed formula of SF (Eq. (8)), the total value of SF is obtained with the addition of magnetic shield coefficient of each layer. It is indicated that the roles in magnetic shielding of each layer are the same and there is no mutual coupling relation, which is consistent with mechanism discussions. The thickness of pure $\mathrm{Fe}$ is $450 \mu \mathrm{m}$, while the total thickness of $\mathrm{Fe}-\mathrm{Ni}$ alloy layer is $50 \mu \mathrm{m}$, which only constitutes $10 \%$ of the total volume. However, the contribution of $\mathrm{Fe}-\mathrm{Ni}$ alloy layer in magnetic shielding under air cooling condition has reached $74.8 \%$, which shows that the magnetic permeability of shield is the key impact factor of magnetic shielding.

In summary, in order to improve the shielding effectiveness of laminated composite, the thickness and magnetic permeability of shield should be increased. When the total thickness of shield remains unchanged, improving the magnetic permeability of shield becomes the main method. In this study, adjusting Ni element content of the surface layer and optimizing heat treatment process can increase magnetic permeability. Another effective approach to improve the shielding effectiveness is by increasing the percentage of high-permeability components in the shield.

\section{Conclusions}

(1) Ni layers were deposited on the surface of pure $\mathrm{Fe}$ substrate and $\mathrm{Fe}-\mathrm{Ni}$ laminated composite with $\mathrm{Fe}-\mathrm{Ni}$ /
$\mathrm{Fe} / \mathrm{Fe}-\mathrm{Ni}$ structure was formed by diffusing heat treatment. The geomagnetic SF arrived at 22.6, seven times higher than that of the Fe substrate.

(2) Through magnetic circuit theory, mathematical formula of SF of laminated composite is obtained. According to the thickness and initial magnetic permeability of each layer, computational value of $\mathrm{SF}$ is obtained, which is slightly higher than the experimental value.

(3) The Fe-Ni laminated composite exhibits excellent magnetic shielding effectiveness by shunting magnetic field with each layer in parallel and there are no mutual coupling relations within these layers.

(4) The thickness and magnetic permeability of shield are the major factors in static magnetic field shielding. Improving magnetic permeability and increasing the thickness of shielding case can improve magnetic shielding effectiveness effectively.

\section{References}

[1] Earth's magnetic field (from Wikipedia, the free encyclopedia, 2014), http://www.en.wikipedia.org/wiki/Earth's_magnetic_ field. Accessed 28 June 2014

[2] S. Koroglu, P. Sergeant, N. Umurkan, Simul. Model. Pract. Theory 18, 206 (2010)

[3] X. Chen, Master Thesis, Harbin Institute of Technology, 2010 (in Chinese)

[4] R. Kannan, S. Ganesan, T.M. Selvakumari, Optoelectron. Adv. Mater. 6, 383 (2012)

[5] Y. Okazaki, M. Lixin, Y. Ohya, J. Mater. Process. Technol. 181, 66 (2007)

[6] G. Haneczok, R. Wroczynski, P. Kwapulinski, A. Chrobak, Z. Stoklosa, J. Rasek, J. Mater. Process. Technol. 209, 2356 (2009)

[7] S.L. Zhao, J. Chen, Y.L. Wang, Acta Metall. Sin. 48, 977 (2012) (in Chinese)

[8] K. Yamazaki, Y. Hatsukade, S. Tanaka, A. Haga, IEEE. Trans. Magn. 44, 4187 (2008)

[9] N. Umurkan, S. Koroglu, O. Kilic, A.A. Adam, Expert Syst. Appl. 37, 3195 (2010)

[10] E. Bulic, A.R. Sinnigoj, B. Cestnik, IEEE. Trans. Electromagn. C. 51, 263 (2009)

[11] C.D. Yu, P. Li, Y.F. Wang, L. Tang, in 2011 International Conference on Mechatronics and Materials Processing, Guangzhou, China, 18-20 November 2011

[12] J.H. Lee, J.W. Jang, S.H. Shon, S.G. Lee, M.S. Park, Mol. Cryst. Liq. Cryst. 470, 107 (2007)

[13] Y.X. Yuan, Mater Thesis, Beijing University of Technology, 2005 (in Chinese)

[14] K.J. Yang, Electromagnetic Compatibility Principle and Design Technique, 2nd edn. (Post \& Telecom Press, Beijing, 2011), pp. $41-47$ 